\title{
Recent advances in psychosocial treatments for borderline personality disorder
}

\author{
Anita Federici* and Shelley McMain
}

\author{
Address: Centre for Addiction and Mental Health, Canada, 33 Russell Street, Toronto, ON M5S 2S1, Canada \\ *Corresponding author: Anita Federici (anita_federici@camh.net) \\ FI000 Medicine Reports 2009, I:5I (doi:I0.34I0/MI-5I)
}

The electronic version of this article is the complete one and can be found at: http://FI000.com/Reports/Medicine/content/I/5 I

\begin{abstract}
In the past three years, several psychosocial treatments for borderline personality disorder have received empirical support. This review highlights findings from recent treatment studies and discusses how these findings have dramatically altered clinical practice for this disorder.
\end{abstract}

\section{Introduction and context}

Historically, borderline personality disorder (BPD) was viewed as a challenging and pervasive mental health disorder that was largely non-responsive to treatment [1]. Given that evidence-based treatments were not available and the fact that many clinicians held pessimistic views about people with the illness, diagnosis of the disorder was typically avoided. Consequently, persons with BPD did not receive adequate care and often experienced mistreatment by health care providers $[1,2]$. Over the past two decades, a growing body of evidence from treatment studies has dramatically altered views about the disorder. Positive results from treatment studies have also facilitated a shift in attitudes and practices for persons with BPD.

\section{Recent advances}

Extensive research findings support the use of a variety of clinical approaches for BPD ranging in theoretical orientation (for example, behaviour therapy, cognitive interventions, or psychodynamic approaches), duration (for example, 12 months or 20 weeks), and application (for example, inpatient, adjunctive treatments, or comorbid-specific). In addition, there are now studies that provide important information regarding the costeffectiveness and long-term clinical outcomes associated with these interventions. The shift toward a more optimistic and compassionate attitude toward individuals with BPD stems largely from a growing body of empirical evidence in support of various approaches.
Cognitive behavioural interventions have received the most empirical support, with dialectical behaviour therapy (DBT) being the most extensively studied and disseminated approach [2,3]. Nine published trials demonstrate that DBT is associated with a significant decrease in the frequency and medical severity of suicidal and self-injurious behaviour, the number of inpatient psychiatric days, and reliance on psychotropic medications [4-12]. Also, trials examining adaptations of DBT across clinical settings and comorbid groups are promising, particularly among inpatient populations [13], adolescents [14], and those with eating disorders [15] and substance abuse $[7,9,11]$.

Despite these impressive results, the standard DBT model (for example, 12 months of weekly individual therapy, skills training, phone skills coaching, and a therapist consultation team) is considered to be a resource-intensive treatment that requires substantial therapist training and involvement $[1,16]$. Unfortunately, most clinical settings lack the resources to apply the comprehensive package and/or train staff accordingly. Given these considerations, there is growing interest in developing and evaluating alternative therapeutic approaches for BPD. For example, alternative cognitive behaviour therapy (CBT)-based approaches, including schema-focused therapy (SFT), have received preliminary empirical support for the treatment of BPD. Although there have been critiques of this study [17], SFT was associated with greater treatment retention and 
superior outcomes at 3 years post-treatment in a controlled multi-site clinical trial compared with transference-focused psychotherapy (TFP) [18]. The costeffectiveness of these two treatments has also been examined, with SFT showing economic advantage over TFP [19]. A large multi-site study comparing 1 year of CBT plus treatment as usual (TAU) to TAU alone for individuals with BPD demonstrated that CBT was associated with superior treatment gains (for example, fewer suicidal behaviours), less symptom distress (for example, a reduction in anxiety and dysfunctional beliefs), and greater cost-effectiveness [20,21].

Interest in the feasibility and cost-effectiveness of the CBT-based STEPPS (Systems Training for Emotional Predictability and Problem Solving) program [22] continues to grow. Designed as an adjunct to ongoing clinical care, STEPPS is a 20 -week manualized group intervention for outpatients meeting diagnostic criteria for BPD. Uncontrolled studies [23,24] and a recent randomized trial [25] have shown that STEPPS is associated with significant improvements across cognitive, emotional, and interpersonal domains. Compared with a control condition, participants exposed to STEPPS reported less impulsivity, a reduction in negative thoughts and feelings, and fewer emergency room admissions. Further support for STEPPS comes from a recently published uncontrolled pilot study in which STEPPS was administered in a forensic setting to 12 female offenders with BPD [26]. Participants reported less distress from BPD-related symptoms and improvements on negative affect and depression.

Additionally, there is growing evidence to support the clinical value of other, brief, skills-based group interventions (typically offered to supplement ongoing or standard care) in the treatment of BPD. Time-limited psychotherapy groups focusing on skill acquisition and adaptive functioning are among the most recognized treatment developments for BPD in recent years. DBTinformed skills training groups, delivered without standard DBT individual therapy, have been studied in several trials and have been shown to be associated with significantly fewer suicidal acts, self-injurious behaviours, and other impulsive self-destructive tendencies (for example, substance abuse, binge eating, and angry outbursts) in patients with BPD [27-29]. Likewise, a sixsession manual-assisted cognitive therapy (MACT) intervention was associated with decreases in the frequency of self-injurious behaviours with treatment gains maintained at 6-month follow-up [30]. Gratz and Gunderson [31] evaluated the clinical effectiveness of a 14-week emotion regulation skills group for the treatment of selfinjurious behaviour in women with BPD. The emotion regulation group incorporated elements from DBT, acceptance and commitment therapy, and emotionfocused therapy, and focused on increasing emotional awareness, decreasing experiential avoidance, and teaching adaptive coping skills. Participants were randomly assigned to receive either the skills group in addition to current treatment or current treatment only. The treatment group showed significant reductions in selfinjurious behaviour and improvements on measures of depression and anxiety, and demonstrated better ability to cope with negative emotions. Finally, education about their diagnosis can also be beneficial to patients diagnosed with BPD. A randomized trial by Zanarini and Frankenburg [32] demonstrated that individuals who were educated about the diagnosis of BPD in a psychoeducation workshop yielded significant improvements in general impulsivity and relational difficulties.

Recently, interest in the evaluation of psychodynamic treatments for BPD has emerged with several dynamically informed approaches demonstrating effectiveness with persons with BPD. TFP, studied in a randomized controlled trial, was compared with DBT and supportive treatment [33]. The three treatments showed comparable reductions on measures of depression, anxiety, and impulsivity, with the TFP and DBT groups showing the greatest reductions in suicidality. Mentalization-based day treatment (MBT) has also been studied and empirically supported in randomized controlled trials $[34,35]$, and a recent follow-up study [36] demonstrated superior maintenance of treatment gains among those who received MBT. Compared with a control group, those assigned to MBT reported fewer suicide attempts, a reduced number of hospital and emergency room visits, a decreased use of psychotropic medications, and greater global functioning 5 years post-treatment. Thus, psychodynamic approaches continue to be among the forefront of innovative and efficacious treatments for BPD.

Efforts to evaluate potential mechanisms and moderaters of change across treatment approaches have also received increased attention in recent years. For instance, researchers have demonstrated the importance of attachment and reflective functioning in TFP [37] and the role of enhanced self-concept and self-affirmation in DBT [38].

\section{Implications for clinical practice}

The rapid and growing interest in developing and evaluating clinical interventions for a population once viewed with reluctance reflects the changing and increasing optimism about this disorder. The growing empirical evidence for the efficacy of various treatment approaches for BPD indicates that it would be 
considered standard clinical practice to encourage and facilitate the assessment and diagnosis of BPD. Moreover, with a greater availability of evidence-based treatments for BPD, potentially more individuals with the disorder will receive empirically supported treatment for their symptoms. Importantly, given that multiple structured approaches are associated with positive clinical changes in BPD, future research establishing mechanisms of change and long-term functioning will be essential $[39,40]$. For example, specific treatment approaches may be more effective with certain patient subgroups and/or levels of motivation for change [41]. While there is evidence for the economic benefit of using several longer-term psychotherapies (for example, DBT, SFT, or TFP), the support for time-limited group therapies is equally salient given the need to develop efficacious interventions that are more easily transportable and cost-effective. A number of treatments for BPD are now manualized to facilitate greater dissemination and easier implementation across clinical settings. Finally, in light of the emerging cost-effectiveness data and the consistent finding that several treatments are associated with decreased pain and suffering among those with BPD, these data have important implications for the provision of health care and medical insurance coverage.

\section{Abbreviations}

$\mathrm{BPD}$, borderline personality disorder; CBT, cognitive behaviour therapy; DBT, dialectical behaviour therapy; MACT, manual-assisted cognitive therapy; MBT, mentalization-based day treatment; SFT, schema-focused therapy; STEPPS, Systems Training for Emotional Predictability and Problem Solving; TAU, treatment as usual; TFP, transference-focused psychotherapy.

\section{Competing interests}

The authors declare that they have no competing interests.

\section{Acknowledgements}

Dr Anita Federici is a Postdoctoral Fellow funded entirely by the Canadian Institutes for Health Research; grant number $200204 \mathrm{MCT}-101123$.

\section{References}

I. Paris J: Outcome and epidemiological research on personality disorders: implications for classification. J Pers Disord 2005, 19:557-62.

2. Linehan MM: Cognitive Behavioural Treatment of Borderline Personality Disorder. New York: Guilford Press; 1993.

3. Lynch TR, Trost WT, Salsman N, Linehan MM: Dialectical behavior therapy for borderline personality disorder. Annu Rev Clin Psychol 2007, 3:I8I-205.

4. Koons CR, Robins CJ, Tweed JL, Lynch TR, Gonzalez AM, Morse JQ, Bishop GK, Butterfield MI, Bastian LA: Efficacy of dialectical behaviour therapy in women veterans with borderline personality disorder. Behav Ther 200I, 32:37I-90.

5. Linehan MM, Armstrong HE, Suarez A, Allmon D, Heard HL: Cognitive-behavioural treatment of chronically parasuicidal borderline patients. Arch Gen Psychiat 1991, 48:1060-4.

6. Linehan MM, Comtois KA, Murray AM, Brown MZ, Gallop RJ, Heard HL, Korsland KE, Tutek DA, Reynolds SK, Lindenboim N: Two-year randomized trial and follow-up of dialectical behaviour therapy vs therapy by experts for suicidal behaviours and borderline personality disorder. Arch Gen Psychiat 2006, 63:757-66.

FI000 Factor 3.0 Recommended

Evaluated by Alec Miller 29 Aug 2006

7. Linehan MM, Dimeff LA, Reynolds SK, Comtois K, Welch SS, Heagerty P, Kivlahan DR: Dialectal behaviour therapy versus comprehensive validation therapy plus 12-step for the treatment of opioid dependent women meeting criteria for borderline personality disorder. Drug Alcohol Depend 2002, 67:13-26.

8. Linehan MM, Heard HL, Armstrong HE: Naturalistic follow-up of a behavioural treatment for chronically parasuicidal borderline patients. Arch Gen Psychiat 1993, 50:971-4.

9. Linehan MM, Schmidt H 3rd, Dimeff LA, Craft JC, Kanter J, Comtois KA: Dialectical behaviour therapy for patients with borderline personality disorder and drug-dependence. $\mathrm{Am} J$ Addict 1999, 8:279-92.

10. Linehan MM, Tutek DA, Heard HL, Armstrong HE: Interpersonal outcome of cognitive behavioural treatment for chronically suicidal borderline patients. Am J Psychiat 1994, I 5 I:177I I-6.

II. van den Bosch LM, Verheul R, Schippers GM, van den Brink W: Dialectical Behaviour Therapy of borderline patients with and without substance abuse problems: implementation and long-term effects. Addict Behav 2002, 27:91।-23.

12. Verheul R, Van Den Bosch LMC, Koeter MWJ, De Ridder MAJ, Stijnen T, Van Den Brink W: Dialectical behaviour therapy for women with borderline personality disorder: 12 month, randomized clinical trial in The Netherlands. Br J Psychiatry 2003, I82: |35-40.

13. Bohus M, Haaf B, Simms T, Limberger M, Schmahl C, Unckel C, Lieb K, Linehan MM: Effectiveness of inpatient dialectical behavioural therapy for borderline personality disorder: a controlled trial. Behav Res Ther 2004, 42:487-99.

14. Rathus JH, Miller AL: Dialectical behavior therapy adapted for suicidal adolescents. Suicide Life-Threat 2002, 32: 146-57.

15. Chen EY, Matthews L, Allan C, Kuo JR, Linehan MM: Dialectical behavior therapy for clients with binge-eating disorder or bulimia nervosa and borderline personality disorder. Int J Eat Disord 2008, 41:505-I2.

FI000 Factor 6.0 Must Read

Evaluated by Glenn Waller II Sep 2008

16. Scheel KR: The empirical basis of dialectical behaviour therapy: summary, critique, and implications. Clin Psychol - Sci Pr 2000, 7:68-86.

17. Yeomans F: Questions concerning the randomized trial of schema-focused therapy vs transference-focused psychotherapy. Arch Gen Psychiat 2007, 64:609-10.

18. Giesen-Bloo J, van Dyck R, Spinhoven P, van Tilburg W, Dirksen C, van Asselt T, Kremers I, Nadort M, Arntz A: Outpatient psychotherapy for borderline personality disorder: randomized trial of schema-focused therapy vs transferencefocused psychotherapy. Arch Gen Psychiat 2006, 63:649-58.

19. van Asselt $A D$, Dirksen $C D$, Arntz A, Giesen-Bloo JH, van Dyck R, Spinhoven P, van Tilburg W, Kremers IP, Nadort M, Severens JL: Outpatient psychotherapy for borderline personality disorder: cost-effectiveness of schema-focused therapy v. transference-focused psychotherapy. Br J Psychiat 2008, 192:450-7.

20. Davidson K, Norrie J, Tyrer P, Gumley A, Tata P, Murray H, Palmer S: The effectiveness of cognitive behavior therapy for 
borderline personality disorder: results from the borderline personality disorder study of cognitive therapy (BOSCOT) trial. J Person Dis 2006, 20:450-65.

21. Palmer S, Davidson K, Tyrer P, Gumley A, Tata P, Norrie J, Murray H, Seivewright $\mathrm{H}$ : The cost-effectiveness of cognitive behavior therapy for borderline personality disorder: results from the BOSCOT trial. J Pers Dis 2006, 20:466-8I.

22. Black DW, Blum N, Pfohl B, St. John D: The STEPPS group treatment program for outpatients with borderline personality disorder. J Contemp Psychol 2004, 34:193-210.

23. Blum N, Pfohl B, John DS, Monahan P, Black D: STEPPS: a cognitive-behavioural systems-based group treatment for outpatients with borderline personality disorder-preliminary report. Compr Psychiat 2002, 43:30I-I0.

24. Freije $H$, Dietz $B$, Appelo $M$ : Behandling van de borderline persoonlijk heidsstoornis met de VERS: de Vaardigheidstraining emotionele regulatiestoornis. Directive Ther 2002, 4:367-78.

25. Blum N, St. John D, Pfohl B, Stuart S, McCormick B, Allen J, Arndt S, Black DW: Systems training for emotional predictability and problem solving (STEPPS) for outpatients with borderline personality disorder: a randomized controlled trial and I-year follow-up. Am J Psychiat 2008, 165:468-78.

FI000 Factor 3.0 Recommended Evaluated by Shelley McMain 14 May 2008

26. Black DW, Blum N, Eichinger L, McCormick B, Allen J, Sieleni B: STEPPS: systems training for emotional predictability and problem solving in women offenders with borderline personality disorder in prison-a pilot study. CNS Spectr 2008, 13:88I-6.

27. Harley RM, Baity MR, Blais MA, Jacobo MC: Use of dialectical behavior therapy skills training for borderline personality disorder in a naturalistic setting. Psychother Res 2007, 17:362-70.

28. Sambrook S, Abba N, Chadwick P: Evaluation of DBT emotional coping skills groups for people with parasuicidal behaviours. Behav Cogn Psychother 2006, 35:24l-4.

29. Safer DL, Telch CF, Agras WS: Dialectical behaviour therapy for bulimia nervosa. Am J Psychiat 200I, I58:632-4.

30. Weinberg I, Gunderson JG, Hennen J, Cutter CJ: Manual assisted cognitive treatment for deliberate self-harm in borderline personality disorder patients. J Pers Disord 2006, 20:482-92.

3I. Gratz KL, Gunderson JG: Preliminary data on an acceptancebased emotion regulation group intervention for deliberate self-harm among women with borderline personality disorder. Behav Ther 2006, 37:25-35.

FI000 Factor 3.0 Recommended

Evaluated by Shelley McMain 27 Sep 2006

32. Zanarini MC, Frankenburg FR: A preliminary, randomized trial of psychoeducation for women with borderline personality disorder. J Pers Disord 2008, 22:284-90.

Changes Clinical Practice

FI000 Factor 3.0 Recommended

Evaluated by Shelley McMain 30 Sep 2008

33. Clarkin JF, Levy KN, Lenzenweger MF, Kernberg OF: Evaluating three treatments for borderline personality disorder: a multiwave study. Am J Psychiat 2007, 164:922-8.

34. Bateman A, Fonagy P: Effectiveness of partial hospitalization in the treatment of borderline personality disorder: a randomized controlled trial. Am J Psychiat 1999, 156:1563-9.

35. Bateman A, Fonagy $P$ : Treatment of borderline personality disorder with psychoanalytically oriented partial hospitalization: an I8-month follow-up. Am J Psychiat 200I, I 58:36-42.

36. Bateman A, Fonagy P: 8-year follow-up of patients treated for borderline personality disorder: mentalization-based treatment versus treatment as usual. Am J Psychiat 2008, I65:63I-8.

FI000 Factor 3.2 Recommended

Evaluated by Mary C Zanarini 03 Jul 2008, Ruth Lanius 0I Apr 2009

37. Levy KN, Meehan KB, Kelly KM, Reynoso JS, Weber M, Clarkin JF, Kernberg OF: Change in attachment patterns and reflective function in a randomized control trial of transferencefocused psychotherapy for borderline personality disorder. J Consult Clin Psychol 2006, 74:1027-40.

38. Bedics JD, Atkins DC, Shaw Welch S, Linehan MM, Schmidt H: Therapeutic process and intrapersonal outcome in dialectical behavior therapy for borderline personality disorder. Poster presented at 40th Annual Convention of the Association for Behavioral and Cognitive Therapies: Nov 2006; Chicago, IL.

39. Gabbard G: Do all roads lead to Rome? New findings on borderline personality disorder. Am J Psychiat 2007, 164:853-5.

40. Levy KN: Psychotherapies and lasting change. Am J Psychiat 2008, 165:556-9.

41. Soler J, Trujols J, Pascual JC, Portella MJ, Barrachina J, Campins J, Tejedor R, Alvarez E, Pérez V: Stages of change in DBT therapy for BPD. Br J Clin Psychol 2008, 47:417-26. 